\title{
Sensitivity and uncertainty analysis of the carbon and water fluxes at the tree scale in Eucalyptus plantations using a metamodeling approach ${ }^{1}$
}

\author{
M. Christina, Y. Nouvellon, J.P. Laclau, J.L. Stape, O.C Campoe, and G. le Maire
}

\begin{abstract}
Understanding the consequences of changes in climatic and biological drivers on tree carbon and water fluxes is essential in forestry. Using a metamodeling approach, sensitivity and uncertainty analyses were carried out for a tree-scale model (MAESPA) to isolate the effects of climate, morphological and physiological traits, and intertree competition on the absorption of photosynthetically active radiation (APAR), gross primary production (GPP), transpiration (TR), light use efficiency (LUE), and water use efficiency (WUE) in clonal Eucalyptus plantations. The metamodel predicting daily TR was validated using one year of sap flow measurements and showed close agreement with the measurements (mean percentage error $=11 \%, n=2155$ ). Simulations showed that APAR, GPP, and TR were very sensitive to the tree morphology and to a competition index representing its local environment. LUE and WUE were, in addition, very sensitive to the natural variability of the physiological leaf and root parameters. A maximum percentage error of $10 \%$ in these parameters leads to $18 \%, 17 \%, 16 \%, 9 \%$, and $18 \%$ uncertainty for APAR, GPP, TR, LUE, and WUE, respectively. The uncertainties in TR were highest for the smallest trees. This study highlighted the need to take account of the spatial and temporal variability of tree traits and environmental conditions for simulations at the tree scale.
\end{abstract}

Key words: metamodeling, surrogate model, process-based model, MAESTRA, eucalypt.

Résumé : En foresterie, il est essentiel de comprendre les conséquences des changements dans les facteurs climatiques et biologiques sur les flux de carbone et d'eau dans les arbres. En utilisant une approche de méta-modélisation, des analyses de sensibilité et d'incertitude ont été effectuées à l'aide d'un modèle à l'échelle de l'arbre (MAESPA) de façon à isoler les effets du climat, des traits morphologiques et physiologiques et de la compétition entre les arbres sur l'absorption du rayonnement photosynthétiquement actif (ARPA), la production primaire brute (PPB), la transpiration (TR), l'efficacité d'utilisation de la lumière (EUL) et l'efficacité d'utilisation de l'eau (EUE) dans des plantations clonales d'eucalyptus. Le méta-modèle de prévision journalière de la TR a été évalué à l'aide du flux de sève mesuré pendant un an et a montré qu'il y avait une relation étroite avec les mesures (pourcentage moyen d'erreur de $11 \%, n=2155$ ). Les simulations ont indiqué que l'ARPA, la PPB et la TR étaient très sensibles à la morphologie des arbres et à un indice de compétition représentant leur environnement local. De plus, l'EUL et l'EUE étaient très sensibles à la variation naturelle des paramètres physiologiques des feuilles et des racines. Un pourcentage maximal d'erreur de 10 \% de ces paramètres a mené à des incertitudes respectives de 18, 17, 16, 9 et 18 \% pour l'ARPA, la PPB, la TR, l'EUL et l'EUE. Les incertitudes de la TR étaient les plus grandes chez les plus petits arbres. Cette étude met en évidence le besoin de prendre en considération la variation spatiale et temporelle des traits des arbres et des conditions environnementales pour les simulations à l'échelle de l'arbre. [Traduit par la Rédaction]

Mots-clés : méta-modélisation, modèle de substitution, modèle fonctionnel, MAESTRA, eucalyptus.

\section{Introduction}

The variability of single-tree growth within a forest is the result of a complex interaction between many different factors, from genetics, through competition between trees, to climatic conditions. The local variability in tree functioning has implications at the stand scale, and "perhaps the most fundamental question in forestry is why one tree grows faster than another" (Binkley et al. 2013). The resources (light, water, and nutrients) available to individual trees will differ from tree to tree and vary with time as a result of competition with other plants and specific local conditions.

Process-based models (PBMs) are likely to become important tools in forestry as they are able to predict the response of trees to

Received 26 September 2015. Accepted 15 December 2015.

M. Christina. UMR Eco\&Sols, CIRAD, 2 place Viala, Montpellier 34060, France; SupAgro Montpellier, 2 place Viala, Montpellier 34060 , France.

Y. Nouvellon. UMR Eco\&Sols, CIRAD, 2 place Viala, Montpellier 34060, France; Departamento de Ciencias Atmosfericas, Universidade de São Paulo, SP, Brazil.

J.P. Laclau. UMR Eco\&Sols, CIRAD, 2 place Viala, Montpellier 34060, France; ESALQ Universidade de São Paulo, Piracicaba, SP, Brazil; Forest Science Department, UNESP, Botucatu, SP, Brazil.

J.L. Stape. Department of Forestry and Environmental Resources, North Carolina State University, Raleigh, NC 27607, USA.

O.C. Campoe. Forestry Science and Research Institute - IPEF, Piracicaba, São Paulo 13418-260, Brazil.

G. le Maire. UMR Eco\&Sols, CIRAD, 2 place Viala, Montpellier 34060, France.

Corresponding author: Mathias Christina (email: mathias.christina@cirad.fr).

${ }^{1}$ This article is part of the special issue "Quantifying uncertainty in forest measurements and models: approaches and applications" associated with the XXIV IUFRO World Congress 2014.

Support for open access for this article was provided by the U.S. National Science Foundation through the QUEST (Quantifying Uncertainty in Ecosystem Studies) Research Coordination Network (http://www.quantifyinguncertainty.org/). This work is licensed under a Creative Commons Attribution 4.0 International License (CC BY 4.0), http://creativecommons.org/licenses/by/4.0/deed.en_GB. 
a range of conditions where empirical data are not available (Landsberg and Sands 2010). Nonetheless, PBMs are sometimes regarded as too complex to be used in forest management, requiring too many parameters (Bartelink and Mohren 2004). Natural and planted forest ecosystems present very variable local environmental conditions and tree characteristics: species, size, total leaf area, spatial distribution of leaves, and many other traits. Some models simplify this local variability by assuming that the parameters and (or) the functions within the stand canopy are uniform (Fontes et al. 2010; Hanson et al. 2004; Burkhart et al. 2012) to obtain simpler PBMs that can be used for forest management (e.g., 3-PG model, Landsberg and Waring 1997; CABALA, Battaglia et al. 2004; G'Day, Comins and McMurtrie 1993; Marsden et al. 2013) and with complexity that depends on the purpose and scale of the study (Battaglia et al. 1998; Pretzsch et al. 2008). These simplified models are commonly used and have been shown to succeed in simulating light interception, gross primary production (GPP), ecosystem respiration, and evapotranspiration in many different types of forests (Hanson et al. 2004). However, they fail to simulate the local variability of tree functioning, which is a key issue for predicting the growth of individual trees in nonuniform forests or to study the impact of forest management practices such as thinning (but see Makela et al. (2000) and Battaglia et al. (2015) for examples of modeling approaches where simple rules are used to disaggregate the stand-level outputs between individual trees). There are some very detailed three-dimensional (3D), structural-functional models that simulate the transpiration, carbon budget, and growth of each tree (and even each leaf) in a stand (Dauzat et al. 2001; Fernández et al. 2011; Griffon and de Coligny 2014), but they are computationally intensive, making long-term simulations difficult.

The computational efficiency of 3D PBMs can be improved by representing individual tree crowns as simple shapes such as ellipsoids or cones (e.g., MAESTRA model, Medlyn 2004; MAESPA model, Duursma and Medlyn 2012). Such models, however, require a larger set of parameters than stand-scale PBMs, thus limiting their use in forestry. When input parameters are unknown, assumptions are often made to estimate their values. One standard approach is setting some tree-scale parameters to values that are the same for all trees or values that do not vary with time. Such simplifications are likely to bias stand-scale simulations and lead to considerable uncertainties at the tree scale, thus representing a major issue for modeling forests at the tree scale. A necessary step in any modeling study is, therefore, to estimate that part of the uncertainty (i.e., the possible error) of the model simulations arising either from a lack of knowledge of parameter values or from deliberate simplifications (Smith 2013). Sensitivity and uncertainty analyses are accurate methods for identifying critical parameters that must be well described through time and (or) space. Only those parameters that vary significantly in space and (or) time and to which the model outputs are sensitive need to be taken into account in the model when simulating spatial and (or) temporal variability (le Maire et al. 2005).

Previous sensitivity analyses of the tree-scale MAESTRA model generally investigated local sensitivity and did not take the natural variability of the parameters into account (Bowden and Bauerle 2008) or were limited to a small number of physiological parameters (e.g., Bauerle and Bowden 2011). Some recent studies have shown the limitations of such local approaches in which the sensitivities of carbon and water fluxes to physiological parameters were strongly influenced by atmospheric $\mathrm{CO}_{2}$ concentration or meteorological conditions such as light or temperature (Bauerle et al. 2014). The soil water balance was introduced in the new version of the model (MAESPA), which affected many of the processes modeled, and the previous sensitivity analysis for MAESTRA must, therefore, be confirmed and extended by taking into account the variability of both tree traits and meteorological conditions. Furthermore, as far as we are aware, no uncertainty analysis of the tree-scale MAESPA model has yet been carried out. Such a study is, by definition, limited to the ecosystem in which the model is applied. This study focused on tropical Eucalyptus plantations because the MAESTRA and MAESPA models have been used extensively in these planted forests (see the bibliography at http://maespa.github.io/bibliography.html), probably owing to the economic importance of eucalypts in tropical regions. Eucalyptus plantations cover more than 20 million hectares around the world and are expanding rapidly in tropical areas (Booth 2013).

The computational cost of complex PBMs is a serious constraint when carrying out global sensitivity analyses. A recent alternative approach is to build a metamodel (or surrogate model), which is a new computationally efficient model that gives almost the same results as the PBM but makes it easier to carry out sensitivity and uncertainty analyses (Faivre et al. 2013). The metamodel approach has recently started to be used in forest modeling to develop faster modules for light interception (Marie and Simioni 2014), biomass prediction (de-Miguel et al. 2014), or land use changes (Gilliams et al. 2005; Sieber et al. 2013.). In addition to facilitating sensitivity analysis, a metamodel of a tree-scale PBM could give simple modules of carbon and water fluxes that are easier to couple with a tree-scale allocation scheme for simulating individual-tree growth.

Wood production is highly dependent on GPP, which is the amount of carbon assimilated by the trees. The dependence of GPP on incident radiation is usually represented by two factors: the amount of PAR absorbed by the tree (APAR) and the light use efficiency (LUE), which indicates how much absorbed light energy is required to produce carbohydrates and, consequently, GPP. GPP also depends on the amount of water used (transpired) by the trees (TR) through water use efficiency (WUE), defined here as the slope of the GPP-TR relationship. This study set out (i) to explore the potential of simple metamodels as an easy means of predicting daily values for APAR, GPP, TR, LUE, and WUE at the tree scale, (ii) to use a metamodel approach to evaluate the sensitivity of the tree-scale MAESPA model outputs to the variability of intertree competition within a stand and to meteorological, physiological, and morphological drivers, and (iii) to estimate the uncertainty of the simulations of GPP, TR, LUE, and WUE at the tree scale resulting from the uncertainty in the input parameters.

\section{Materials and methods}

\subsection{Study site and measurements}

The site was a 90 ha Eucalyptus plantation located in southeastern Brazil (São Paulo State) at $22^{\circ} 58^{\prime} 04^{\prime \prime} \mathrm{S}$ and $48^{\circ} 43^{\prime} 40^{\prime \prime} \mathrm{W}, 750 \mathrm{~m}$ above sea level, and managed as part of the Eucflux project (http:// www.ipef.br/eucflux/en/). A highly productive E. grandis clone was planted in November 2009 at an average spacing of $3 \mathrm{~m}$ between rows and $2 \mathrm{~m}$ within each row (1666 trees.ha $\left.\mathrm{h}^{-1}\right)$ using standard forestry practices for Brazilian commercial Eucalyptus plantations (Gonçalves et al. 2013). Eucalyptus plantations in Brazil, and particularly in this region, are among the most productive forests in the world (Nouvellon et al. 2012) and are generally harvested at 6 years of age. Four permanent plots of 84 trees were inventoried at ages $5,6,9,12,15,18,21,25,31$, and 37 months to measure tree height $(\mathrm{H})$ and diameter at breast height (DBH). Destructive sampling of 10 trees (taken from outside the permanent plots) at each date were carried out to determine the allometric relationship for tree leaf area $(L A)$, crown diameter $\left(D_{C}\right)$, and crown height $\left(H_{C}\right)$, following the methodology described in detail in le Maire et al. (2013). Leaf inclination angles (LIA) were measured at 1, 2, and 3 years after planting using a clinometer. At each age, LIA was measured on 10 trees of different sizes (72 leaves per tree). Vertical leaf area density distribution was calculated using the leaf area in the bottom, medium, and upper third of the crown using destructive sampling. The horizontal leaf area distribution was measured as part of another experiment with the same Eucalyptus species (Christina et al. 2015). Photosynthesis parameters used in the MAESPA model were measured for six trees (photosynthesis - internal leaf $\mathrm{CO}_{2}$ concentra- 
tion $\left(A-C_{\mathrm{i}}\right)$ curves for estimating $J_{\mathrm{MAX}}, V_{\mathrm{CMAX}}, R_{\mathrm{d}}$, as defined in Table 1) or three trees (photosynthesis-irradiance (A-PAR) curves for estimating $\alpha$ and $\theta$, as defined in Table 1) of different heights, using a portable gas exchange system (LI-COR 6400, LI-COR Inc., Lincoln, Nebraska, USA). For each tree, these photosynthesis parameters were measured at different heights within the crown (bottom, middle, and upper parts of the crown) and for two horizontal positions within the crown (inner and outer parts of the crown). Water content reflectometers (CS616, Campbell Scientific, Shepshed, UK) were used to measure the soil water content every metre down to $10 \mathrm{~m}$ depth over the first 5 years after planting. Half-hourly meteorological data (Table 1 ) were collected at the top of an eddy-flux tower in the same stand as the four permanent plots, from January 2010 to December 2014.

\subsection{MAESPA presentation}

The MAESPA model (Duursma and Medlyn 2012) coupled the soil water balance components of the SPA model (Williams et al. 1996) to the MAESTRA model (Medlyn 2004), with some major changes and additions. MAESTRA was a 3D single-tree and stand process-based model that calculated light interception and distribution within crowns and used a leaf physiology submodel to estimate photosynthesis and transpiration. The 3D model for calculating APAR was based on Norman and Welles (1983) and is described in other studies (Medlyn 1998). The spatial position, crown dimension, and total leaf area of each tree of the stand were fixed as inputs in the model. APAR was calculated for specified "target" trees in the stand, taking into account the neighboring trees competing for light. The crown was discretized in a 3D grid with a given number of horizontal layers and a given number of points per layer. For each point in the grid, the leaf area was defined using normalized beta distributions. A single leaf inclination distribution was specified for all trees within the stand. At each grid point, after calculating the PAR absorption, photosynthesis and transpiration were calculated using a combined stomatal conductance - photosynthesis - transpiration model based on Farquhar et al. (1980) for $\mathrm{CO}_{2}$ assimilation and Tuzet et al. (2003) for stomatal conductance. The APAR, GPP, and TR were calculated for each target tree at a half-hourly time step. The water balance submodel was derived largely from the SPA model (Williams et al. 1996). The soil profile comprised various horizontally uniform soil layers with specific characteristics and root densities (no competition between trees). The water balance submodel was based on the water potential of the soil, roots, leaves, and air and on the hydraulic conductivities between these different compartments. Transpiration was calculated by combining two methods, the first based on the Penman-Monteith equation applied to small volumes of leaves and the second based on the equations computing the water flow from the soil to the leaves. The leaf water potential was estimated iteratively by matching these two calculations of the transpiration rate and was used to compute the stomatal conductance (Tuzet et al. 2003). The water content in each soil layer was calculated from infiltration, drainage, root water uptake, and soil evaporation at the same time step as the aboveground processes (half-hourly). Except for the soil water content, there are no memory effects in the model.

\subsection{Building first-level metamodels of MAESPA for tree- scale APAR, GPP, TR, LUE, and WUE}

For the global sensitivity and uncertainty analyses, metamodels for APAR, GPP, TR, LUE, and WUE were set up as a first simplification of the computationally intensive MAESPA model. These metamodels were based on empirical formulae and simplified parameter sets. A flowchart of the method used to build these first-level metamodels is given in Fig. 1A.

\subsubsection{Setting up 1500 virtual random stands}

A large number of realistic virtual stands are required for calibrating the MAESPA metamodels. These must cover the widest possible range of virtual stands with trees of different morphologies and physiologies. Different meteorological conditions representative of the climate also need to be selected. Fifteen-hundred Eucalyptus stands of 576 trees ( 24 rows $\times 24$ trees per row) were generated pseudo-randomly. It has been shown that a purely random sampling is not the most computationally cost-efficient method for calibrating metamodels or for uncertainty and sensitivity analyses (Marino et al. 2008). Using stratified sampling is likely to provide more efficient coverage of the parameter space. Consequently, Latin hypercube sampling (LHS, Mckay et al. 2000) was used to provide an efficient distribution of parameter values with only 1500 scenarios. For each scenario, the average DBH within the stands and the morphological and physiological parameters at the stand scale were estimated. The ranges used in the LHS for the values of these parameters are shown in Table 1. Once the average DBH had been estimated, a realistic virtual stand was built with the DBH of each tree in the virtual stand being determined using a random normal distribution and a competition index (CI; Hegyi 1974; Mailly et al. 2003). The method is described in the section "Tree positions and DBH" of the Supplementary material. ${ }^{2}$ The tree morphology (height, leaf area, etc.) was then calculated from the DBH using allometric relationships. Each virtual plantation was associated with half-hourly meteorological parameters for a given day, randomly selected from 5 years of data, to use the real variability of the meteorological parameters and the correlation that often occurs between them within a day.

\subsubsection{MAESPA simulations}

MAESPA simulations were performed in each virtual stand for one day. Simulations were performed on one target tree chosen at random from the central part of the stand ( 16 rows $\times 16$ trees per row), discarding the external four rows of trees in each stand to avoid border effects. APAR, GPP, TR, LUE, and WUE for that tree were calculated at half-hourly time steps and cumulated over the day to give the daily total APAR, GPP, TR, LUE, and WUE for 1500 different trees in 1500 different virtual stands.

\subsubsection{Polynomial first-level metamodels}

The 1500 simulations performed with the MAESPA metamodel were used to build metamodels for APAR, GPP, TR, LUE, and WUE at a daily time step based on second-order polynomial regressions (Barton and Meckesheimer 2006; Faivre et al. 2013). Two types of pararmeter were used to calibrate the metamodels: (i) MAESPA input parameters such as the leaf area or photosynthetic capacity of the tree and (ii) simplified or aggregated MAESPA input parameters such as the half-hourly meteorological input parameters, which were aggregated into average daily conditions. The parameters describing all the neighboring trees were reduced to Hegyi's CI (Hegyi 1974; Mailly et al. 2003; see Supplementary material ${ }^{2}$ ). In total, there were 37 parameters (Table 1). For example, for GPP the polynomial equation was

$$
\begin{array}{r}
\operatorname{GPP}(X)=\alpha_{0}+\sum_{j=1}^{K}\left(\alpha_{j} X_{j}+\beta_{j} X_{j}^{2}\right)+\sum_{j=1}^{K} \sum_{k=j+1}^{K} \gamma_{j k} X_{j} X_{k}+\varepsilon, \\
\varepsilon \sim N\left(0, \sigma^{2}\right)
\end{array}
$$

where $X_{j}\left(\right.$ or $X_{k}$ ) are one of the 37 parameters and $\alpha_{0}, \alpha_{j}, \beta_{j}$, and $\gamma_{j k}$ are the regression coefficients.

\footnotetext{
${ }^{2}$ Supplementary material is available with the article through the journal Web site at http://nrcresearchpress.com/doi/suppl/10.1139/cjfr-2015-0173.
} 
Table 1. List of parameters used for constructing the MAESPA metamodels with their symbols and definitions, as well as the range of values and references.

Parameter Description and units

Competition parameter

CI Competition index ( $\mathrm{m}^{-1}$; Heigy 1974)

\section{Meteorological parameters}

SWC Average soil water content at the beginning of the day $\left(\mathrm{m}^{3} \cdot \mathrm{m}^{-3}\right)$

RAD Daily global radiation $\left(\mathrm{W} \cdot \mathrm{m}^{-2}\right)$

$\mathrm{T}_{\mathrm{AIR}} \quad$ Daily average air temperature $\left({ }^{\circ} \mathrm{C}\right)$

RH Daily average relative humidity (\%)

Press Daily average atmospheric pressure $(\mathrm{kPa})$

Wind Daily average wind speed $\left(\mathrm{m} \cdot \mathrm{s}^{-1}\right)$

$F_{\text {BEAM }} \quad$ Beam fraction of PAR

PPT $\quad$ Daily precipitation $\left(\mathrm{mm} \cdot \mathrm{day}^{-1}\right)$

\section{Morphological parameters}

DBH Diameter at breast height $(\mathrm{cm})$

$\mathrm{H} \quad$ Tree height $(\mathrm{m})$

LA Tree leaf area $\left(\mathrm{m}^{2}\right)$

$D_{\mathrm{C}} \quad$ Crown diameter $(\mathrm{m})$

$\mathrm{H}_{\mathrm{C}} \quad$ Crown height $(\mathrm{m})$

LIA Average leaf inclination angle $\left({ }^{\circ}\right)$

$\mathrm{LAD}_{\mathrm{V}} \quad$ Relative height within the crown of the maximum of vertical leaf area density

$\mathrm{LAD}_{\mathrm{H}} \quad$ Relative distance from trunk of the maximum of horizontal leaf area density

Bearing Bearing of the $x$ axis from south $\left({ }^{\circ}\right)$

\section{Physiological parameters}

$g_{0} \quad$ Minimum stomatal conductance $\left(\mathrm{mol} \cdot \mathrm{m}^{-2} \cdot \mathrm{s}^{-1}\right)$

$g_{1} \quad$ Slope between stomatal conductance and photosynthesis (unitless)

$S_{\mathrm{f}} \quad$ Slope of the response to leaf water potential $\left(\mathrm{MPa}^{-1}\right)$

$\Psi_{\mathrm{w}} \quad$ Reference water potential (MPa)

$J_{\text {MAX }} \quad$ Maximum rate of photosynthetic electron transport at $25^{\circ} \mathrm{C}\left(\mu \mathrm{mol} \cdot \mathrm{m}^{-2} \cdot \mathrm{s}^{-1}\right)$

$V_{\mathrm{CMAX}} \quad$ Maximum rate of Rubisco carboxylase activity at $25^{\circ} \mathrm{C}\left(\mu \mathrm{mol} \cdot \mathrm{m}^{-2} \cdot \mathrm{s}^{-1}\right)$

$R_{\mathrm{d}} \quad$ Dark respiration at $25^{\circ} \mathrm{C}\left(\mu \mathrm{mol} \cdot \mathrm{m}^{-2} \cdot \mathrm{s}^{-1}\right)$

$\alpha \quad$ Quantum yield of electron transport $\left(\mathrm{mol} \cdot \mathrm{mol}^{-1}\right)$

Trans

Refl

Curvature parameter of the light response of photosynthesis (unitless)

Leaf transmittance

Leaf reflectance

Leaf width $(\mathrm{m})$

$K_{\mathrm{P}}$

Leaf-specific total plant conductivity $\left(\mathrm{mmol} \cdot \mathrm{m}^{-2} \cdot \mathrm{s}^{-1} \cdot \mathrm{MPa}^{-1}\right)$

\section{root parameters}

$R_{\mathrm{RAD}} \quad$ Root radius $(\mathrm{mm})$

SRL Specific root length $\left(\mathrm{m} \cdot \mathrm{g}^{-1}\right)$

RMD Root mass density $\left(\mathrm{g} \cdot \mathrm{m}^{-2}\right)$

$R_{\text {Depth }} \quad$ Maximum root depth (m)

$R_{\text {Dis }} \quad$ Root distribution using the beta parameter of Jackson et al. 1996

Average residual SWC $\left(\mathrm{m}^{3} \cdot \mathrm{m}^{-3}\right)$

Range of values Source or details

3 to 8

0.1 to 0.2

18 to 370

10 to 27

34 to 99

91.8 to 93.8

0.3 to 6

0 to 0.5

0 to 124

4 to 18

4 to 20

1 to 90

2 to 5

4 to 14

20 to 80

0.2 to 0.8

0.2 to 0.7

-180 to 180

0.01 to 0.08

5 to 20

0.4 to 6

-1 to -3

60 to 230

40 to 126

0.3 to 3

0.2 to 0.4

0.2 to 1

0.01 to 0.1

0.025 to 0.27

0.02 to 0.06

0.2 to 3

0.1 to 1

5 to 80

40 to 1100

2.5 to 18

0.94 to 0.99

0.08 to 0.18
Calculated based on tree density

Taken from a 5-year dataset

This study

le Maire et al. 2013; Christina et al. 2015; this study

This study

Medlyn et al. 2007; Barnard and Bauerle 2013; Christina et al. 2015

Tuzet et al. 2003

Grassi et al. 2002; Whitehead and Beadle 2004; Medlyn et al. 2007;

Wullschleger 1993; Christina et al. 2015; this study

Grassi et al. 2002; Medlyn et al. 2007; Alcorn et al. 2008; Christina et al. 2015; this study

Grassi et al. 2002; Medlyn et al. 2007; Christina et al. 2015; this study

Grassi et al. 2002; Christina et al. 2015; this study

Richards and Schmidt 2010; le Maire et al. 2013

Christina et al. 2015

Christina et al. 2011; Christina et al. 2015

Christina et al. 2011

This study; Christina et al. 2011

Marsden et al. 2013; Christina et al. 2015; this study 
Fig. 1. Flowchart of (A) the method used to build the MAESPA metamodels and (B) their use in the global sensitivity and uncertainty analysis. Separate first-level metamodels were built for tree-absorbed photosynthetically active radiation (APAR), gross primary production (GPP), transpiration (TR), light use efficiency (LUE), and water use efficiency (WUE). Some of the parameters used by the metamodels were simplified. For example, the daily average temperature was used in the metamodels, whereas the hourly temperature was required in the MAESPA model. The second-level metamodel was obtained by removing the least sensitive parameters.

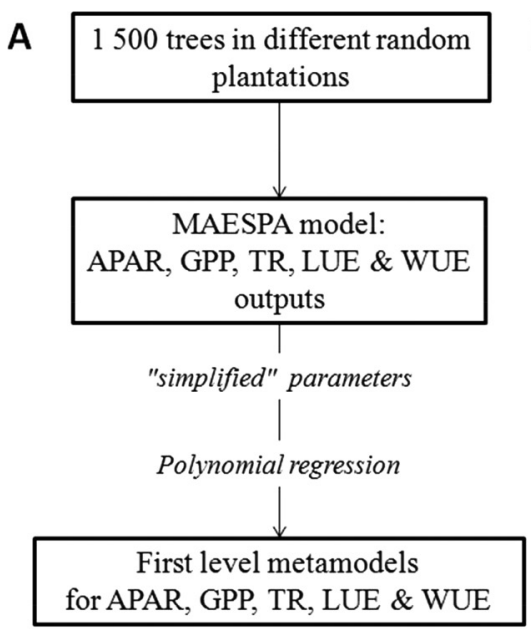

To limit the large number of possible two-way interactions between the 37 parameters, stepwise regression based on the Akaike information criterion (AIC) was used to remove nonsignificant interactions. Interactions were omitted if this did not significantly increase the AIC. For the particular case of APAR, the metamodel was built with only the parameter that had an influence on APAR in the model (competition index, morphological and meteorological parameters, as well as leaf transmittance and reflectance). The accuracy of the different first-level metamodels was evaluated through $R$-squared $\left(R^{2}\right)$ and root mean square error (RMSE).

\subsection{Global sensitivity analysis}

The first-level metamodels were accurate (see Results) and could be used as substitutes for the MAESPA model for sensitivity analyses, considerably increasing the calculation speed. A global sensitivity analysis of the APAR, GPP, TR, LUE, and WUE metamodels was performed using the Sobol approach (Sobol 1993), which gives an estimate of the sensitivity based on the variance of the output. This time, 10000 trees were randomly sampled from 10000 different virtual stands built using the method described above (see section 1.3.1 and Supplementary material ${ }^{2}$ ). Taking the example of GPP, the main sensitivity index $\left(S_{i}\right)$ of the $i$ th parameter $\left(X_{i}\right)$ for GPP was calculated as follows:

$$
S_{i}=\frac{\operatorname{Var}\left(\mathrm{E}\left(\mathrm{GPP} \mid X_{i}\right)\right)}{\operatorname{Var}(\mathrm{GPP})}
$$

where the numerator is the variance of the expected GPP knowing the value of the parameter $\left(X_{i}\right)$ and the denominator is the variance of GPP. This is the contribution of $X_{i}$ to the GPP variance and represents the effect of varying $X_{i}$ alone. A total sensitivity index $\left(\mathrm{ST}_{i}\right)$ for each parameter was also calculated. $\mathrm{ST}_{i}$ was the sum of the main sensitivity index for parameter $i$ and the sensitivity of the parameter $i$ in interaction with all the other parameters, expressed as

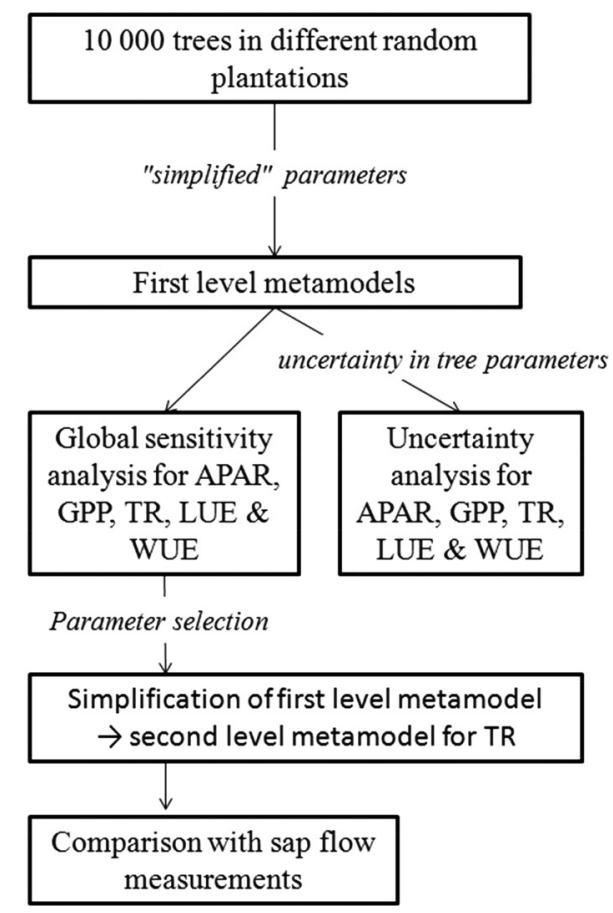

(3) $\quad \mathrm{ST}_{i}=1-\frac{\operatorname{Var}\left(\mathrm{E}\left(\mathrm{GPP} \mid \mathrm{X}_{-i}\right)\right)}{\operatorname{Var}(\mathrm{GPP})}$

where the numerator is the effect of varying all parameters except $X_{i}$. Consequently, the sensitivity of the interaction of parameter $i$ with all the other parameters $\left(\mathrm{Int}_{i}\right)$ was calculated as the difference between $\mathrm{ST}_{i}$ and $S_{i}$. Sobol sensitivity indices for individual parameters were calculated with R.4.0 (package "sensitivity", function sobol2007 or sobol; R Foundation for Statistical Computing, Vienna, Austria, http://www.r-project.org).

\subsection{Local uncertainty analysis}

\subsubsection{Local uncertainty analysis for one particular tree}

A local uncertainty analysis of the first-level metamodels for APAR, GPP, TR, LUE, and WUE was performed, for illustrative purposes, on one tree chosen from the tree database used in the global sensitivity analysis. The aim of the local uncertainty analysis was an estimation of the output error due to measurements uncertainty and was therefore performed on little variations. It was possible that the values of the morphological, physiological, and root parameters of this particular tree might be over- or under-estimated, leading to uncertainties on the model outputs. Note that the CI parameter of the model could also be over- or under-estimated as a result of errors in the neighboring tree sizes and positions. Account was not taken of possible errors in meteorological variables in this analysis because they are difficult to quantify and probably much smaller than the uncertainties on other parameters.

The uncertainty was expressed as the mean absolute percentage error for maximum error values from $0 \%$ to $10 \%$, with a 0.5 percentage point step to test the linearity of the relationship between model uncertainty and error in parameter values. For example, for a maximum error in the parameters of $\pm 5 \%$, the value of each parameter varied in a uniform probability distribution from $-5 \%$ 
to $+5 \%$ around its initial value (the error could be zero). Fivethousand simulations of the models were run with 5000 scenarios using LHS of the parameters between these $5 \%$ limits. The APAR, GPP, TR, LUE, or WUE outputs were then compared with the simulations of the tree with all parameters set to their initial values (zero error). For a single tree $i$ and a 5\% maximum error, the mean absolute percentage error $\left(\mathrm{MAPE}_{\text {treei,5\%}}\right)$ was calculated as follows (example for GPP):

$$
\mathrm{MAPE}_{\mathrm{GPP}, \text { tree }, 5 \%}=\frac{1}{5000} \sum_{j=1}^{5000} \frac{\left|\mathrm{GPP}_{\text {error } 5 \%, j}-\mathrm{GPP}_{\text {ini }}\right|}{\mathrm{GPP}_{\text {ini }}}
$$

where $\mathrm{GPP}_{\text {ini }}$ is the GPP simulation with the original set of parameter (no error) and GPP error $5 \%, j_{j}$ is the GPP for the $j$ th scenario with maximum variations from $-5 \%$ to $+5 \%$.

\subsubsection{Generalization of the uncertainty analysis to trees of all ages}

Because the uncertainty in APAR, GPP, TR, LUE, and WUE may depend on the set of initial values of parameters selected, the uncertainty analysis for a single tree was repeated for eight trees with different DBHs and then for all 10000 trees in the global sensitivity dataset, which covers trees from 6 months old to 3 years old. The median, 10th, and 90th percentiles of the uncertainty are shown as a function of the maximum error in the parameters and as a function of DBH in Fig. 4.

\subsection{Second-level metamodel for TR and comparison with measurements}

After the global sensitivity analysis, a second-level metamodel for TR was built (Fig. 1B) by pruning the same parameter set as used in the first-level metamodel. The aim was to include the least possible number of parameters to facilitate the presentation and the use of the metamodel without adversely affecting the general performance. This metamodel was obtained by removing parameters that had a Sobol index less than 0.02 in the first-level metamodel. Predictions from the second-level metamodel for TR were compared with daily-averaged sap flow measured for individual trees over one year in another E. grandis plantation. This second site was located $15 \mathrm{~km}$ from the Eucflux study site. The structure of this second plantation was comparable with the Eucflux site in terms of tree density and tree age (Christina et al. 2015). Sap flow was measured for 10 trees representing the whole range of DBH from January to December 2012. Every tree was equipped with a sensor protected from external temperature variations and water intrusion by a reflective foil. The sensor output voltage was recorded every $30 \mathrm{~s}$, and the average was stored every $30 \mathrm{~min}$ (CR1000 dataloggers and AM16/32 multiplexers, Campbell Scientific Inc., Logan, Utah, USA). The sap flow density was calculated using a calibration equation taking into account the thermal dissipation of the sensors for E. grandis trees (Delgado-Rojas et al. 2010). The mean percentage errors between the model predictions and the measurements were calculated for daily, weekly, monthly, and annual time scales. For example, the daily mean percentage error for tree transpiration $\left(\mathrm{MPE}_{\mathrm{TR}, \text { Day }}\right)$ was calculated as

$$
\mathrm{MPE}_{\mathrm{TR}, \text { Day }}=\frac{1}{N} \sum_{i=1}^{N} \frac{\mathrm{TR}_{\text {DaySim }, i}-\mathrm{TR}_{\text {DayMeas }, i}}{\mathrm{TR}_{\text {DayMeas }, i}}
$$

where $N$ is the number of trees, $\mathrm{TR}_{\text {Daysim, } i}$ is the daily simulated transpiration of tree $i$ and $\mathrm{TR}_{\text {DayMeas, } i}$ is the daily measured transpiration of tree $i$.

In addition, the measurements were compared with the MAESPA model predictions, which had been precisely parameterized for this study site in a previous study (Christina et al. 2015).

\section{Results}

\subsection{Global sensitivity analysis of APAR, GPP, TR, LUE, and} WUE

The first-level metamodels for APAR, GPP, TR, LUE, and WUE reproduced MAESPA predictions accurately (Fig. 2). The best fits for metamodels were found for APAR $\left(R^{2}=0.92\right.$, RMSE $=$

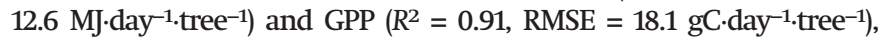
while the fit accuracy was lower for TR $\left(R^{2}=0.84, \mathrm{RMSE}=9.4 \mathrm{~L}\right.$ $\left.\mathrm{H}_{2} \mathrm{O} \cdot \mathrm{day}^{-1} \cdot \mathrm{tree}^{-1}\right)$, LUE $\left(R^{2}=0.87, \mathrm{RMSE}=0.20 \mathrm{gC} \cdot \mathrm{MJ}^{-1}\right)$, and WUE $\left(R^{2}=0.77, \mathrm{RMSE}=1.13 \mathrm{gC} \cdot \mathrm{L} \mathrm{H}_{2} \mathrm{O}^{-1}\right)$.

APAR, GPP, and TR were very sensitive to meteorological parameters (Fig. 3). In particular, APAR and GPP were sensitive to global radiation $(R A D)$ and the beam fraction of radiation $\left(F_{\text {BEAM }}\right)$. TR was also sensitive to soil water content at the beginning of the day (SWC), air temperature $\left(\mathrm{T}_{\mathrm{AIR}}\right)$, and relative humidity $(\mathrm{RH})$. Moreover, tree APAR, GPP, and TR were sensitive to morphological parameters such as tree leaf area (LA) and height $(H)$, as well as the close environment of the tree (competition index, CI). GPP was also sensitive to the parameters controlling the photosynthetic capacity of the leaves $\left(J_{\text {MAX }}, V_{\text {CMAX }}\right.$, and quantum yield $\alpha$ ). TR was highly sensitive to physiological parameters controlling the tree $\left(K_{\mathrm{P}}\right)$ and leaf $\left(g_{0}, g_{1}\right.$, and $\left.\Psi_{\mathrm{W}}\right)$ conductivities and, to a lesser extent, by root mass density (RMD).

Tree light use efficiency (LUE) was highly sensitive to meteorological parameters, with a much higher sensitivity to $F_{\text {BEAM }}$ and SWC than GPP. LUE was also highly sensitive to physiological parameters, in particular, the minimum stomatal conductance $\left(g_{0}\right), J_{\mathrm{MAX}}$, $V_{\text {CMAX }}, \alpha$, and $\theta$. LUE was less sensitive to morphological (LA, LIA, $\mathrm{LAD}_{\mathrm{V}}$, and $\mathrm{LAD}_{\mathrm{H}}$ ) and root (RMD and $\theta_{\mathrm{R}}$ ) parameters. LUE was not strongly affected by $\mathrm{CI}$, indicating that GPP was sensitive to $\mathrm{CI}$ through light absorption only.

Tree water use efficiency (WUE) was highly sensitive to many meteorological and physiological parameters. Some meteorological parameters also affected TR (SWC, RAD, TAIR, $F_{\text {BEAM }}$ ), but unlike TR, WUE was also highly sensitive to relative air humidity $(\mathrm{RH})$ and wind speed (Wind). WUE was highly sensitive to $\mathrm{g}_{0}$ and $K_{\mathrm{P}}$, as well as to interactions with $J_{\mathrm{MAX}}, V_{\mathrm{CMAX}}, R_{\mathrm{d}}$, and Refl. WUE was also sensitive to root parameters such as RMD and $\theta_{\mathrm{R}}$ but insensitive to $\mathrm{CI}$ and morphological parameters.

\subsection{Local uncertainty analysis of GPP, TR, LUE, and WUE}

The local uncertainty of the MAESPA metamodel predictions resulting from errors in the input parameters varied between trees. A few examples of uncertainties for a few trees are given in Table 2. The uncertainty, expressed in mean absolute percentage error $\left(\mathrm{MAPE}_{\text {tree }}\right)$, depended on the initial values of the tree parameters. These examples show that the output uncertainty was strongly dependent on the tree being simulated. The variability in the uncertainties in the predicted values of GPP, TR, LUE, and WUE for 10000 different trees depended on the output and the error in the parameters (Fig. 4A). With a maximum error in the parameters of $10 \%$, the median $\mathrm{MAPE}_{\text {tree }}$ was $18 \%, 17 \%, 16 \%, 8 \%$, and $18 \%$ for APAR, GPP, TR, LUE, and WUE, respectively, with uncertainty values up to $40 \%$ for APAR, GPP, TR, and WUE for certain trees (Fig. 4A). The uncertainty was linearly dependent on the error up to $10 \%$ maximum error.

The median uncertainty increased slightly with tree DBH for APAR, GPP, and LUE simulations. It was independent of tree size for WUE (Fig. 4B). For TR, the median uncertainty slightly decreased with tree $\mathrm{DBH}$, and the variability of the uncertainty was much higher for trees with a DBH less than $8 \mathrm{~cm}$.

\subsection{Validation of the second-level metamodel for TR}

After removing parameters with low sensitivity indices, the second-level metamodel used only 11 parameters. The sensitivity indices for these parameters are shown in Fig. 5A. Annual simulations of TR using this daily metamodel at the tree scale over one 
Fig. 2. Comparison of the MAESPA and the first-level metamodel simulations for (A) daily absorbed photosynthetically active radiation (APAR), (B) gross primary production (GPP), (C) transpiration (TR), (D) light use efficiency (LUE), and (E) water use efficiency (WUE). The kernel density estimations of simulations are shown by shading (blue in online version). The $R^{2}$ and RMSE are presented for each metamodel ( $\left.n=1500\right)$. (This figure is available in colour online.)
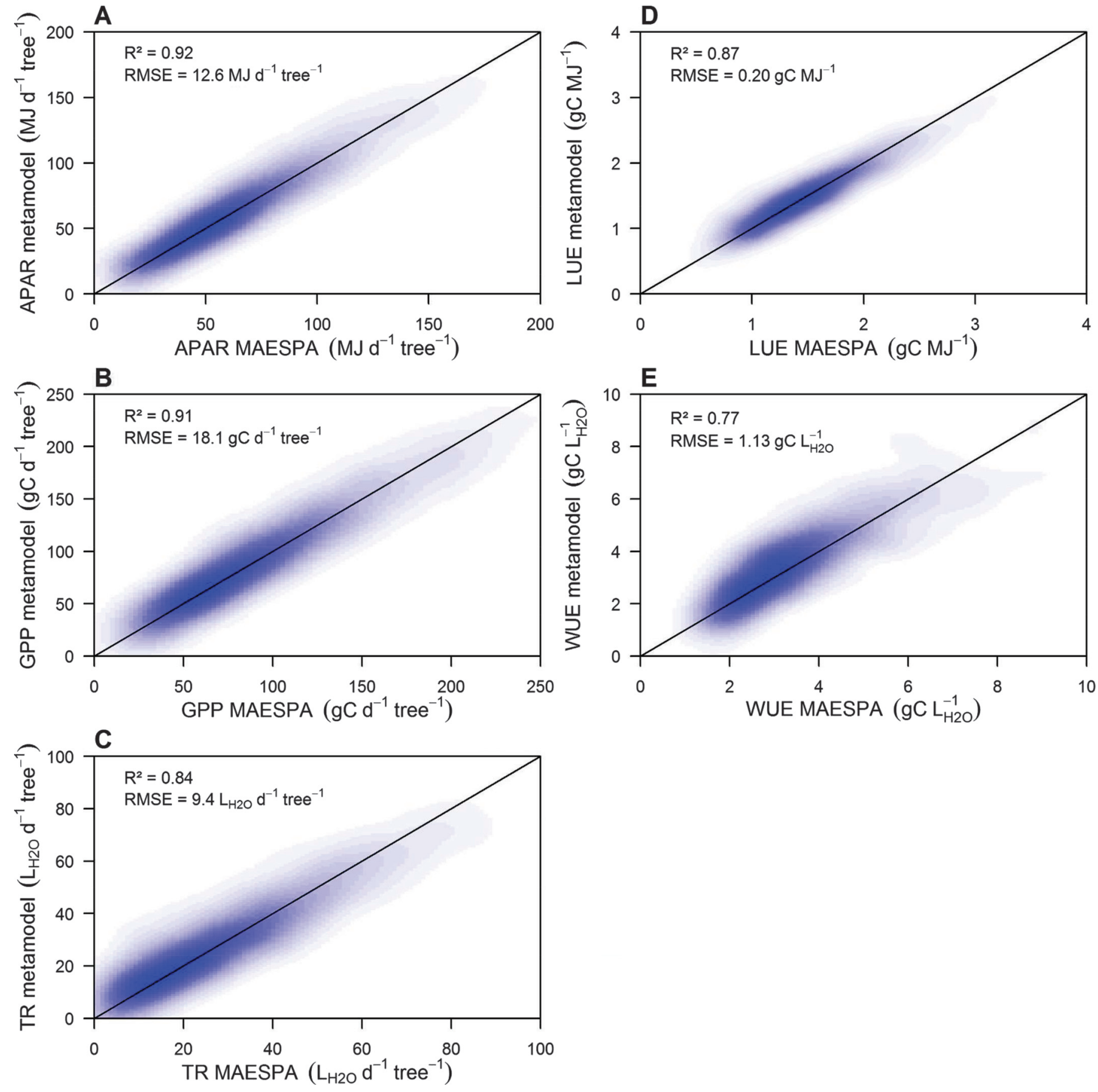

year showed good agreement with the measured sap flow (Fig. 5B). The tree transpiration time series was well represented, with a slight decrease during the dry season in the middle of the year. The accuracy of transpiration simulations depended on the simulation time scale (Fig. 5C). At the daily time scale, the average mean percentage error at tree scale (MPE) was $11 \%$, with a strong variability depending on the tree simulated and the day. The MPE decreased as the time scale increased. The MPE for tree-scale TR simulations fell to $9 \%$ for weekly and monthly simulations and $4 \%$ for annual simulations. The MAESPA model showed the same accuracy at the daily time scale (MPE 11\%) but was slightly better

for weekly and monthly simulations (MPE 6\%) and annual simulations (MPE 2\%).

\section{Discussion}

\subsection{Dealing with temporal and spatial parameter variability} for tree-scale modeling

\subsubsection{Tree-scale parameter variability}

Unlike the traditional view of uniform Eucalyptus planted forests, this study highlights the need to take the local variability of the trees into account to give an accurate prediction of carbon and 
Fig. 3. Global sensitivity analysis of the first-level MAESPA metamodels for daily absorbed photosynthetically active radiation (APAR), gross primary production (GPP), transpiration (TR), light use efficiency (LUE), and water use efficiency (WUE). The sensitivity to the individual parameters was estimated using the Sobol index. The sensitivity to the interaction with all other parameters was calculated as the difference between the total sensitivity index (ST) and the main sensitivity index (S) (eqs. 2 and 3). Individual parameters are grouped into meteorological (Meteo.), morphological (Morpho.), physiological (Physio.), and root (Roots) parameters. $R^{2}$ for each metamodel is shown in the column heading; "+" and "-" indicate whether the relationship between the input parameter and the output value is positive or negative; 10000 daily simulations were performed in the sensitivity analysis. (This figure is available in colour online.)

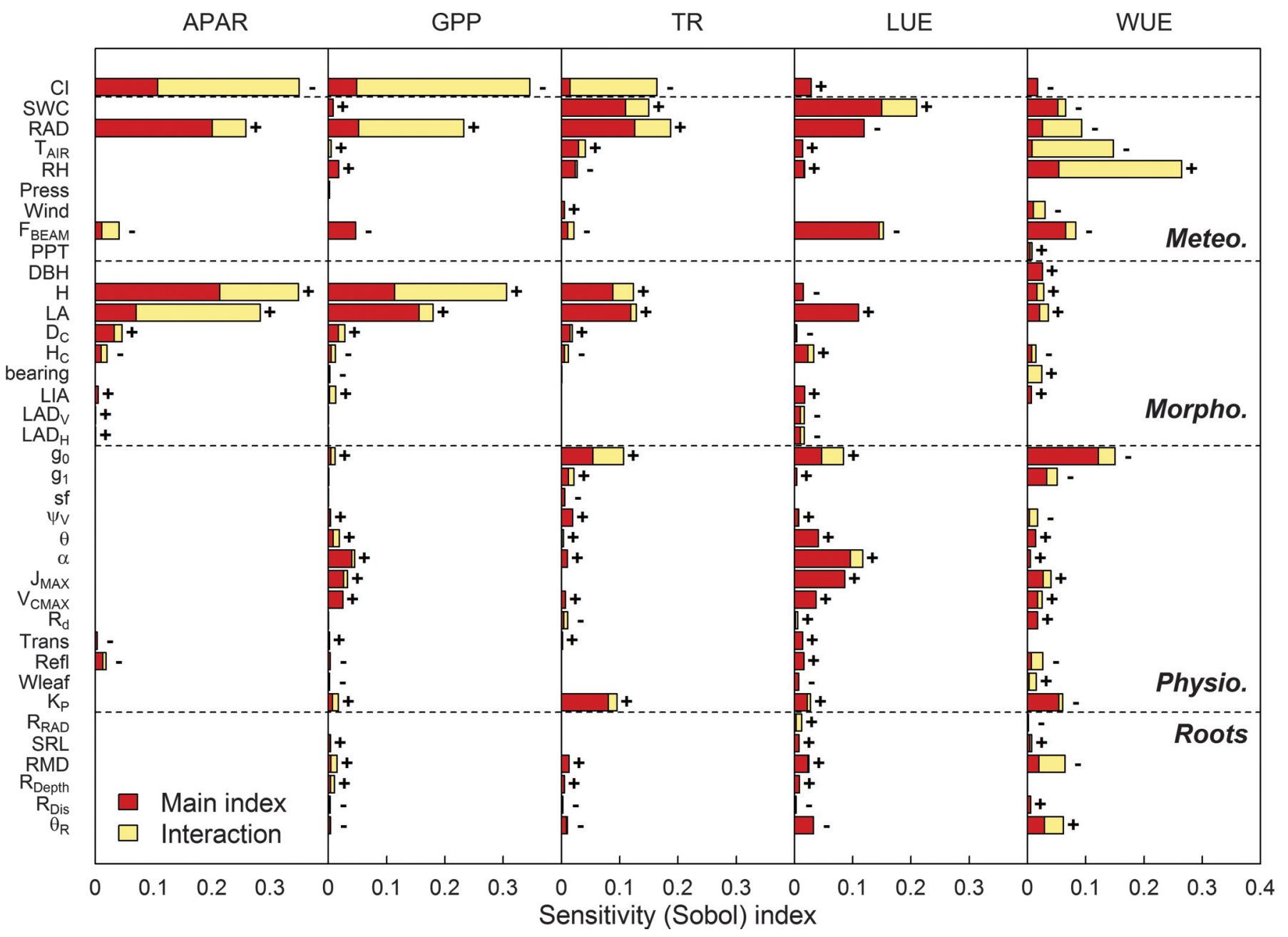

Table 2. Uncertainty in daily tree absorbed photosynthetically active radiation (APAR, MJ.day ${ }^{-1} \cdot$ tree $^{-1}$ ), gross photosynthesis (GPP, g C.day ${ }^{-1}$.tree ${ }^{-1}$ ), transpiration (TR, $\mathrm{L} \mathrm{H}_{2} \mathrm{O} \cdot$ day $^{-1} \cdot$ tree $^{-1}$ ), light use efficiency (LUE, $\mathrm{g} \mathrm{C}^{\mathrm{MJ}} \mathrm{J}^{-1}$ ), and water use efficiency (WUE, $\mathrm{g} \mathrm{C} \cdot \mathrm{L} \mathrm{H}_{2} \mathrm{O}^{-1}$ ) for eight trees sampled with different diameters at breast height ( $\mathrm{DBH}$, as a proxy of tree age), for a $\pm 5 \%$ or a $\pm 10 \%$ maximum error on morphological, physiological, and root parameters. The single-tree output value is given for zero error and the uncertainty is expressed as mean absolute percentage error (MAPE $\mathrm{tree}, x \%_{\text {) }}$ ).

\begin{tabular}{|c|c|c|c|c|c|}
\hline \multirow[b]{2}{*}{ Tree DBH $(\mathrm{cm})$} & \multicolumn{5}{|c|}{ Single-tree output value ( $\left.\pm \mathrm{MAPE}_{\text {tree }, x \%}, \%\right)$} \\
\hline & $\begin{array}{l}\text { APAR } \\
\left(\mathrm{MJ} \cdot \mathrm{day}^{-1} \cdot \mathrm{tree}^{-1}\right)\end{array}$ & $\begin{array}{l}\text { GPP } \\
\left(\text { g C } \text { day }^{-1} \cdot \text { tree }^{-1}\right)\end{array}$ & $\begin{array}{l}\text { TR } \\
\left(\mathrm{L} \mathrm{H}_{2} \mathrm{O} \cdot \text { day }^{-1} \cdot \text { tree }^{-1}\right)\end{array}$ & $\begin{array}{l}\text { LUE } \\
\left(\mathrm{g} \mathrm{C}^{\mathrm{M}} \mathrm{MJ}^{-1}\right)\end{array}$ & 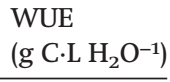 \\
\hline \multicolumn{6}{|l|}{$x=5 \%$ error } \\
\hline 6 & 41 ( $\pm 5 \%)$ & $57.5( \pm 4 \%)$ & $16.2( \pm 8 \%)$ & $1.39( \pm 3 \%)$ & $3.83( \pm 5 \%)$ \\
\hline 8 & $27( \pm 8 \%)$ & $52.9( \pm 8 \%)$ & $36.8( \pm 5 \%)$ & $1.66( \pm 4 \%)$ & $1.67( \pm 14 \%)$ \\
\hline 12 & $54( \pm 11 \%)$ & $76.2( \pm 16 \%)$ & $24.3( \pm 12 \%)$ & $1.44( \pm 6 \%)$ & $3.09( \pm 9 \%)$ \\
\hline 14 & 69 ( $\pm 12 \%)$ & $90.0( \pm 15 \%)$ & $33.1( \pm 13 \%)$ & $1.23( \pm 8 \%)$ & $3.07( \pm 12 \%)$ \\
\hline \multicolumn{6}{|l|}{$x=10 \%$ error } \\
\hline 7 & $53( \pm 12 \%)$ & $69.7( \pm 15 \%)$ & $17.7( \pm 18 \%)$ & $1.42( \pm 8 \%)$ & $4.12( \pm 21 \%)$ \\
\hline 9 & $41( \pm 12 \%)$ & $60.1( \pm 18 \%)$ & $16.2( \pm 22 \%)$ & $1.45( \pm 8 \%)$ & $3.73( \pm 10 \%)$ \\
\hline 11 & $33( \pm 32 \%)$ & $87.8( \pm 32 \%)$ & $27.6( \pm 19 \%)$ & $1.96( \pm 8 \%)$ & $2.56( \pm 22 \%)$ \\
\hline 13 & $107( \pm 24 \%)$ & $136.2( \pm 20 \%)$ & $33.5( \pm 20 \%)$ & $1.28( \pm 14 \%)$ & $3.09( \pm 22 \%)$ \\
\hline
\end{tabular}


Fig. 4. Uncertainty analysis of the MAESPA metamodels for daily tree absorbed radiation (APAR), gross photosynthesis (GPP), transpiration (TR), light use efficiency (LUE), and water use efficiency (WUE). Uncertainty is expressed in mean absolute percentage error of the output for a single tree $\left(\mathrm{MAPE}_{\text {tree }}\right)$ as a function of the maximum error applied to model parameters $(\mathrm{A})$ or as a function of the tree DBH (B). The black lines indicate the medians of $\mathrm{MAPE}_{\text {tree }}$ calculated for 10000 trees, and the 10th and 90th percentiles enclose the shaded area; 5000 daily simulations were performed for each of the 5000 trees in the uncertainty analysis.

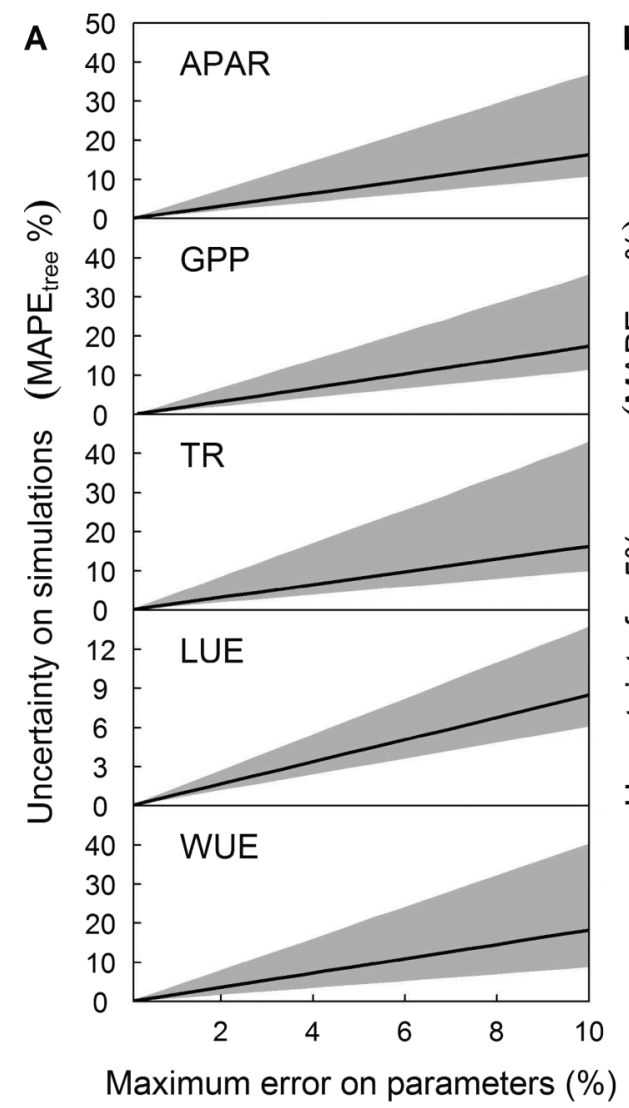

water fluxes at the tree scale in monoclonal plantations. This local variability results from both intertree competition for resources (light, water, and nutrients) and morphological tree traits.

Competition between trees has commonly been used as an empirical indicator (e.g., for the effect of thinning, Forrester et al. $2013 a$ ) or as a predictor (e.g., Vanclay 2006) of tree growth in Eucalyptus planted forests. This study showed that a competition index can be used in metamodels to replace and (or) describe some processes of competition for light commonly used in PBMs. Carbon and water fluxes in this study were highly sensitive to Hegyi's CI (Hegyi 1974). This competition index reflects the effect of the size of the surrounding trees (based on their DBH) relative to the size of the target tree, as well as the effect of the distance from the target tree. Smaller trees of a stand are generally associated with a high competition index, as observed in our Eucalyptus plantations (described in eq. S3 in the Supplementary material2). Many competition indices have been used in the literature. While distance-dependent indices are not always the best indicators of growth (e.g., Biging and Dobbertin 1995), they are generally useful proxies (Contreras et al. 2011). This dependence on the competition index emphasizes the importance of taking surrounding trees into account to predict carbon and water fluxes at the tree scale, even in relatively uniform clonal Eucalyptus plantations.

Another component of the local variability that appeared important for predicting carbon and water fluxes was the variability of the crown architecture. For example, leaf inclination angles (LIA) and leaf area density had a significant effect on light use efficiency. Plants adapted to low light environments tend to have more horizontal leaves than those adapted to sunlight (McMillen

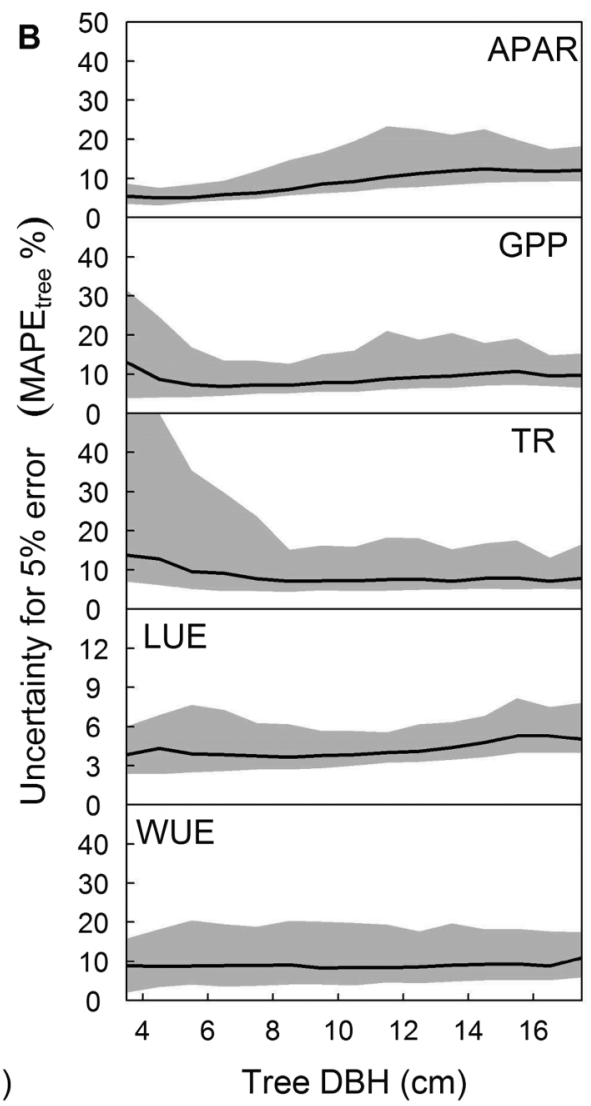

and McClendon 1979; King 1997). This behavior has also been observed in Eucalyptus plantations at the experimental site, where suppressed trees had more horizontal leaves than dominant trees (data not shown). Similar behavior was observed within the tree crown, where leaves at the bottom of the crown were more horizontal than upper leaves (le Maire et al. 2011). The same attention should be paid to parameters describing leaf distribution within the crown, which might vary between clones or sites (Alcorn et al. 2013).

While a simple indicator such as the competition index may be sufficient for predicting tree growth in empirical models or metamodels, it is important that certain morphological tree traits (in particular tree height and leaf area) and the distance between trees are accurately parameterized when simulating the carbon and water fluxes in complex tree-scale PBMs such as MAESPA. Other morphological tree traits do not require as much accuracy (e.g., crown height for predicting GPP in this study). Dimensions of trees within planted forests are generally estimated through allometric relationships (O'Brien et al. 1995), which are often associated with high uncertainties (Chave et al. 2014). Multiple allometric relationships calibrated for different ages and for different plots are needed for tree-scale PBMs. Some previous studies of light use with the MAESTRA or MAESPA model assumed a nominal position for trees within the stands (Christina et al. 2015; le Maire et al. 2013), while others estimated the tree position using in situ measurements, aerial photography, or very high resolution satellite images (Charbonnier et al. 2013; Forrester et al. 2013b; Gspaltl et al. 2013). The assumption of a regular spacing could bias 
Fig. 5. Validation of the MAESPA second-level metamodel of tree transpiration (TR). (A) Sensitivity of the metamodel to parameters using the Sobol index, (B) time series of daily simulated tree transpiration and sap flow measurements from 1.5 to 2.5 years after planting, and (C) mean percentage error, with standard deviation, between simulated and measured tree TR depending on the time scale. The lines in B show the average of 10 trees, and the grey areas are the standard deviations. The TR simulations of the original MAESPA models (Christina et al. 2015) were also compared with measurements $(C)$. (This figure is available in colour online.)
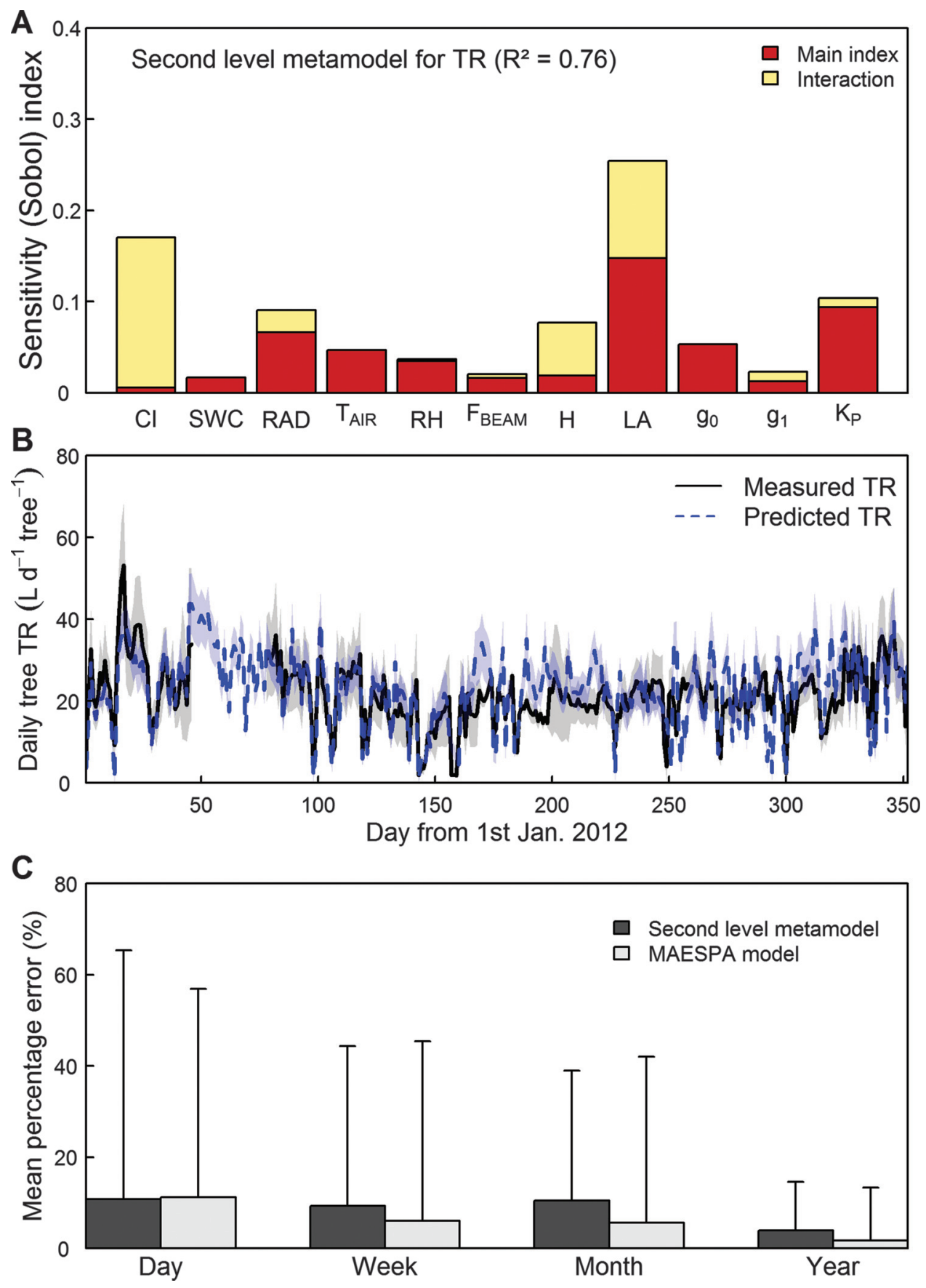

the competition environment of the trees and, in consequence, the prediction of carbon and water fluxes at the tree scale.

\subsubsection{Parameters set constant across the stand}

This study highlights the importance of some parameters that are commonly held constant between trees in PBMs for accurate predictions of carbon and water fluxes at the tree scale.

Parameters controlling stomatal conductance and plant conductance had, as expected, a significant effect on TR, WUE, and LUE. While high sensitivity to $g_{1}$ (the slope between the GPP and TR), as shown by Bauerle and Bowden (2011), was expected, the minimum stomatal conductance $\left(g_{0}\right)$ had a greater effect on TR, LUE, and WUE. While $g_{0}$ has commonly been assumed to be close to zero with little effect on water fluxes (Caird et al. 2007; Zeppel et al. 2010), recent studies have shown that $g_{0}$ could be higher than previously expected in many ecosystems (Ogle et al. 2012) and that its value could change seasonally (Barnard and Bauerle 2013). In a recent study using MAESTRA, it was shown that $g_{0}$ had a large effect on TR (Bowden and Bauerle 2008). Stomatal conductance is driven by $g_{0}$ or $g_{1}$ depending on the assimilation $(A)$ conditions in the Ball-Berry type model of Tuzet et al. (2003) $\left(g_{\mathrm{s}}=g_{0}+g_{1} \cdot A / C_{\mathrm{s}} \cdot f\left(\Psi_{\text {leaf }}\right)\right.$, where $C_{\mathrm{s}}$ is the $\mathrm{CO}_{2}$ 
concentration at the stomata surface and $f\left(\Psi_{\text {leaf }}\right)$ is a function of the leaf water potential). Bauerle et al. (2014) showed that the importance of $g_{0}$ depended on the meteorological conditions. For instance, TR was more sensitive to $g_{0}$ in low light (e.g., in canopies with a high LAI) than in high light conditions. A lower sensitivity to $g_{1}$ and a higher sensitivity to $g_{0}$ have also been observed for red maple, which has a higher LAI (Bauerle and Bowden 2011). In these low photosynthesis situations, $g_{s}$ is mostly driven by $g_{0}$. The high sensitivity to $g_{0}$ in the Eucalyptus plantation in this study supports the conclusions of Barnard and Bauerle (2013), who stressed the necessity of measuring $g_{0}$ accurately. An estimate of $g_{0}$ using linear extrapolation from stomatal conductance model regression underestimated the minimum stomatal conductance by more than $50 \%$ compared with direct measurements.

This study showed that the photosynthetic parameters (within the range of values measured at the site) had little effect on TR. Photosynthetic parameters may affect $g_{s}$, as assimilation is one of the parameters used to calculate $g_{\text {s }}$ in the Ball-Berry model of stomatal conductance. Nevertheless, for conditions of low assimilation (A) (e.g., when the irradiance is low) or low $f\left(\Psi_{\text {leaf }}\right.$ ) (when leaf water potential is low), $g_{0}$ dominates the $g_{s}$ calculation. GPP, LUE, and, to a lesser extent, WUE were, however, highly sensitive to $J_{\mathrm{MAX}}, V_{\mathrm{CMAX}}$, and quantum yield $(\alpha)$. Bauerle et al. (2014) underlined that, in the Farquhar model, the sensitivity to photosynthetic parameters was dynamic in response to light and temperature changes owing to the transitory nature of light versus $\mathrm{CO}_{2}$ limitations. In low light conditions, photochemical reactions (influenced by $J_{\text {MAX }}$ and $\alpha$ ) will limit photosynthesis. For strong light conditions or under water stress (which decreases substomatal $\mathrm{CO}_{2}$ concentrations as the stomata close), it is more likely that photosynthesis will be limited by the carboxylation capacity. The influence of $\alpha$ seems rather more complex, but evidence suggests that $\alpha$ could have a higher influence on photosynthesis than $J_{\text {MAX }}$ or $V_{\text {CMAX }}$ under low light conditions and high temperatures (Bauerle et al. 2014) .

The fine root parameters also affected the predictions at the tree scale even though they were constant across the stand. In the model, fine root biomass affects the water status of trees, affecting the leaf water potential and, consequently, $f\left(\Psi_{\text {leaf }}\right)$, stomatal conductance, and WUE. Root parameters are very difficult to measure, and the use of typical values constant in time and space is generally assumed a priori. However, this study showed that fine roots have to be accurately measured to give reliable predictions of WUE. Moreover, although not having a great effect in the short term, long-term variations (as a result of tree growth) of root traits such as root distribution could result in large changes in carbon and water fluxes in Eucalyptus plantations.

\subsubsection{Variability of meteorological parameters with time}

The variability of meteorological parameters with time was a major factor driving APAR, GPP, TR, LUE, and WUE predictions at the tree scale. Meteorological parameters showed a high variability over the year owing to seasonal changes, as well as day-to-day variability.

Some of these parameters had the effects that were expected on carbon and water fluxes. This was the case, for example, for the effect of global radiation (RAD) on GPP and the effect of soil water content (SWC) on TR. The relative humidity (RH) had little effect on GPP and TR but a major effect on WUE. This is explained by the stomatal conductance, which scales linearly with photosynthesis (depending on the atmospheric $\mathrm{CO}_{2}$ concentration at the leaf surface), and the slope between them is strongly dependent on the relative humidity.

The beam fraction $\left(F_{\mathrm{BEAM}}\right)$ strongly affected carbon and water fluxes by decreasing LUE and WUE. This is recognized behavior in natural and planted forests. In boreal, temperate, and tropical forests, Alton et al. (2007) showed that LUE increased from $6 \%$ to $33 \%$ when incoming global radiation was dominated by diffuse light, and a similar trend was reported by Zhou et al. (2011) for temperate, subtropical, and tropical forests in China. This is partly explained by the fact that the diffuse light tends to cause less saturation of photosynthesis in individual leaves in the canopy (Gu 2002; Charbonnier et al. 2013). $F_{\text {BEAM }}$ affected GPP in this study, but this effect was limited as, even though a lower $F_{\text {BEAM }}$ tend to increase LUE, it is generally associated with a decrease in global radiation (RAD). The beam fraction of incoming light is often estimated using the approximation of Spitters et al. (1986) based on total incident global radiation (Forrester et al. 2013b; le Maire et al. 2013; Forrester and Albrecht 2014; Christina et al. 2015). The high sensitivity of the model to this parameter alone suggests that studies dealing with LUE should measure $F_{\text {BEAM }}$ to high precision (e.g., Charbonnier et al. 2013) rather than approximate it.

\subsection{The use of metamodels in forestry}

This study developed a metamodeling approach for carrying out sensitivity analyses of complex, computationally intensive PBMs for trees. While such an approach has already been used with success in engineering disciplines and for energy analyses (Marrel et al. 2009; Tian 2013), it is not common in PBMs field of research, especially for sensitivity analysis purposes. In engineering studies, the commonly used metamodels for sensitivity analysis use regression splines, smoothing operators, or Gaussian processes (Tian 2013). This study showed that polynomial metamodels could be used as surrogates for complex tree-scale PBMs for evaluating the sensitivity of carbon and water fluxes, as well as the uncertainties.

One major objective of metamodeling is to obtain simple and parsimonious modules compared with the original PBMs. The second-level metamodel presented in this study gave accurate predictions of carbon and water fluxes at the tree scale using far fewer parameters than the original MAESPA model, while keeping the interactions between them. For example, a complete parameterization of MAESPA would require $\sim 200$ parameters to fully parameterize 24 trees, but the simple second-level metamodel for TR required only 11 parameters because shading trees are summarized by the competition index. In the current study, second-level metamodels for APAR, GPP, LUE, and WUE were also created but were not presented in this article due to the unavailability of a proper validation dataset. Similarly to our second-level metamodel, simple metamodels are generally built after removing parameters with low sensitivity and by using aggregated parameters (e.g., Lafond et al. 2015). The difference between our approach and the one of Lafond et al. (2015) is that they performed the sensitivity analysis on the original model and built a metamodel using the selected inputs, while we have built our first metamodel using almost all inputs of the original model and simplified it afterwards.

Metamodels are also often used as powerful tools to obtain surrogate models much faster than the original models. As an example, Marie and Simioni (2014) built a metamodel of the light interception module of a forest PBM (no TG) 62 times faster than the original model. However, the use of metamodels is not limited to speeding up a model; it could also be used for model coupling. For example, a metamodel for tree light interception could be coupled with tree-scale PBMs, which simulate growth of individual, rather than computing light interception at the canopy scale (e.g., GOTILWA+ model, Keenan et al. 2008). Similarly, simple metamodels for tree light use efficiency could be coupled with tree-scale PBMs of tree growth by using the light use efficiency as an input (e.g., PICUS model, Seidl et al. 2005). This approach of combining models and metamodels has already been applied at the stand scale. For example, Härkönen et al. (2010) and Härkönen et al. (2011) used a summary model of light use efficiency to estimate whole canopy GPP as a function of climatic conditions in various pine and spruce forests in Finland. Nevertheless, metamodels are usually only applicable to the species and parameter space for which they were calibrated. More general metamodels could be developed by increasing the parameter space, but their 
accuracy would be more difficult to assess as they must be tested in many different types of forests and under many different climatic conditions.

\section{Conclusion}

Using metamodels for sensitivity analyses showed that carbon and water fluxes at the tree scale in Eucalyptus plantations are controlled by key sets of parameters that were different for APAR, GPP, TR, LUE, and WUE. Uncertainty in the measurements of morphological, physiological, and fine root parameters could cause a significant uncertainty in APAR, GPP, TR, LUE, and WUE. This study showed that the natural variability of both tree traits and meteorological conditions must be taken into account in global sensitivity analyses. Moreover, metamodeling was shown to be a powerful method for future process-based modeling studies for forests, reducing the degree of complexity of the original model without significant loss of precision.

\section{Acknowledgements}

This project was funded by the University of São Paulo, the Centre de coopération Internationale en Recherche Agronomique pour le Développement (CIRAD), the EUCFLUX project, the Agence Nationale de la Recherche (MACACC project ANR-13-AGRO-0005, Viabilité et Adaptation des Ecosystèmes Productifs, Territoires et Ressources face aux Changements Globaux AGROBIOSPHERE 2013 program), USP-COFECUB (Project 2011-25), AGREENIUM (Plantrotem project), and SOERE F-ORE-T). We are grateful to Juan Sinforiano Delgado-Rojas and Patricia Battie-Laclau for field measurements, as well as the staff at the Itatinga Experimental Station, in particular, Rildo Moreira e Moreira (Esalq, USP) and Eder Araujo da Silva (http:// www.floragroapoio.com.br) for their technical support. We are grateful to Tony Tebby for correcting the English language.

\section{References}

Alcorn, P.J., Bauhus, J., Thomas, D.S., James, R.N., Smith, R.G.B., and Nicotra, A.B. 2008. Photosynthetic response to green crown pruning in young plantationgrown Eucalyptus pilularis and E. cloeziana. For. Ecol. Manage. 255: 3827-3838. doi:10.1016/j.foreco.2008.03.030.

Alcorn, P.J., Forrester, D.I., Smith, R.G.B., Thomas, D.S., James, R.N., Nicotra, A.B., and Bauhus, J. 2013. Crown structure and vertical foliage distribution in 4-year-old plantation-grown Eucalyptus pilularis and Eucalyptus cloeziana. Trees, Structure Function, 27: 555-566. doi:10.1007/s00468-012-0809-1.

Alton, P.B., North, P.R., and Los, S.O. 2007. The impact of diffuse sunlight on canopy light-use efficiency, gross photosynthetic product and net ecosystem exchange in three forest biomes. Glob. Chang. Biol. 13: 776-787. doi:10.1111/ j.1365-2486.2007.01316.x.

Barnard, D.M., and Bauerle, W.L. 2013. The implications of minimum stomatal conductance on modeling water flux in forest canopies. J. Geophys. Res. Biogeosciences 118: 1322-1333.

Bartelink, H.H., and Mohren, G.M.J. 2004. Modelling at the interface between scientific knowledge and management issues. In Towards the Sustainable Use of Europe's Forests - Forest Ecosystem and Landscape Research: Scientific Challenges and Opportunities. EFI Proceedings 49. pp. 21-30.

Barton, R.R., and Meckesheimer, M. 2006. Metamodel-based simulation optimization. In Handbooks in Operations Research and Management Science. Vol. 13. Simulation. Elsevier. pp. 535-574.

Battaglia, M., and Sands, P.J. 1998. Process-based forest productivity models and their application in forest management. For. Ecol. Manage.102: 13-32.

Battaglia, M., Sands, P., White, D., and Mummery, D. 2004. CABALA: a linked carbon, water and nitrogen model of forest growth for silvicultural decision support. For. Ecol. Manage. 193: 251-282. doi:10.1016/j.foreco.2004.01.033.

Battaglia, M., Bruce, J., Latham, R., O'Grady, A., and Greenwood, A. 2015. Processbased size-class distribution model of trees within forest plantations: a hierarchical modeling approach. For. Ecol. Manage. 344: 63-72. doi:10.1016/j. foreco.2015.02.015.

Bauerle, W.L., and Bowden, J.D. 2011. Separating foliar physiology from morphology reveals the relative roles of vertically structured transpiration factors within red maple crowns and limitations of larger scale models. J. Exp. Bot. 62: 4295-4307. doi:10.1093/jxb/err156. PMID:21617246.

Bauerle, W.L., Daniels, A.B., and Barnard, D.M. 2014. Carbon and water flux responses to physiology by environment interactions: a sensitivity analysis of variation in climate on photosynthetic and stomatal parameters. Clim. Dyn. 42: 2539-2554. doi:10.1007/s00382-013-1894-6.

Biging, G.S., and Dobbertin, M. 1995. Evaluation of competition indices in individual tree growth models. For. Sci. 41: 360-377.
Binkley, D., Laclau, J.P., and Sterba, H. 2013. Why one tree grows faster than another: patterns of light use and light use efficiency at the scale of individual trees and stands. For. Ecol. Manage. 288: 1-4. doi:10.1016/j.foreco.2012.08. 009.

Booth, T.H. 2013. Eucalypt plantations and climate change. For. Ecol. Manage. 301: 28-34. doi:10.1016/j.foreco.2012.04.004.

Bowden, J.D., and Bauerle, W.L. 2008. Measuring and modeling the variation in species-specific transpiration in temperate deciduous hardwoods. Tree Physiol. 28: 1675-1683. doi:10.1093/treephys/28.11.1675. PMID:18765372.

Burkhart, H.E., and Tomé, M. 2012. Modeling forest trees and stands. Springer Science and Business Media, Dordrecht, the Netherlands.

Caird, M.A., Richards, J.H., and Donovan, L.A. 2007. Nighttime stomatal conductance and transpiration in C3 and C4 plants. Plant Physiol. 143: 4-10. PMID: 17210908.

Charbonnier, F., le Maire, G., Dreyer, E., Casanoves, F., Christina, M., Dauzat, J., Eitel, J.U.H., Vaast, P., Vierling, L.A., and Roupsard, O. 2013. Competition for light in heterogeneous canopies: application of MAESTRA to a coffee (Coffea arabica L.) agroforestry system. Agric. For. Meteorol. 181: 152-169. doi:10.1016/ j.agrformet.2013.07.010.

Chave, J., Réjou-Méchain, M., Búrquez, A., Chidumayo, E., Colgan, M.S., Delitti, W.B.C., Duque, A., Eid, T., Fearnside, P.M., Goodman, R.C., Henry, M., Martínez-Yrízar, A., Mugasha, W.A., Muller-Landau, H.C., Mencuccini, M., Nelson, B.W., Ngomanda, A., Nogueira, E.M., Ortiz-Malavassi, E., Pélissier, R., Ploton, P., Ryan, C.M., Saldarriaga, J.G., and Vieilledent, G. 2014. Improved allometric models to estimate the aboveground biomass of tropical trees. Glob. Chang. Biol. 20: 3177-3190. doi:10.1111/gcb.12629. PMID:24817483.

Christina, M., Laclau, J.P., Gonçalves, J.L.M., Jourdan, C., Nouvellon, Y., and Bouillet, J.P. 2011. Almost symmetrical vertical growth rates above and below ground in one of the world's most productive forests. Ecosphere 2: 1-10.

Christina, M., Le Maire, G., Le Battie-Laclau, P., Nouvellon, Y., Bouillet, J.-P., Jourdan, C., de Moraes Gonçalves, J.L., and Laclau, J.-P. 2015. Measured and modeled interactive effects of potassium deficiency and water deficit on gross primary productivity and light-use efficiency in Eucalyptus grandis plantations. Glob. Chang. Biol. 21: 2022-2039. doi:10.1111/gcb.12817. PMID:25430918.

Comins, H.N., and McMurtrie, R.E. 1993. Long-term response of nutrient-limited forests to $\mathrm{CO}_{2}$ enrichment: equilibrium behavior of plant-soil models. Bull. Ecol. Soc. Am. 3: 666-681.

Contreras, M.A., Affleck, D., and Chung, W. 2011. Evaluating tree competition indices as predictors of basal area increment in western Montana forests. For. Ecol. Manage. 262: 1939-1949. doi:10.1016/j.foreco.2011.08.031.

Dauzat, J., Rapidel, B., and Berger, A. 2001. Simulation of leaf transpiration and sap flow in virtual plants: model description and application to a coffee plantation in Costa Rica. Agric. For. Meteorol. 109: 143-160. doi:10.1016/S01681923(01)00236-2.

Delgado-Rojas, J.S., Laclau, J., Roupsard, O., Stape, J., Ranger, J., Bouillet, J., and Nouvellon, Y. 2010. Calibration of home-made heat dissipation probes for a full rotation of Eucalyptus grandis trees in Brazil. American Geophysical Union, Fall Meeting 2010, Abstract H31B-0992.

de-Miguel, S., Mehtätalo, L., and Durkaya, A. 2014. Developing generalized, calibratable, mixed-effects meta-models for large-scale biomass prediction. Can. J. For. Res. 44: 648-656. doi:10.1139/cjfr-2013-0385.

Duursma, R.A., and Medlyn, B.E. 2012. MAESPA: a model to study interactions between water limitation, environmental drivers and vegetation function at tree and stand levels, with an example application to $\left[\mathrm{CO}_{2}\right] \times$ drought interactions. Geosci. Model Dev. 5: 919-940. doi:10.5194/gmd-5-919-2012.

Faivre, R., Iooss, B., Mahévas, S., Makowski, D., and Monod, H. 2013. Exploration par construction de métamodèles. In Analyse de Sensibilité et Exploration de Modèles, Applications Aux Sciences de La Nature et de L'environnement, Versailles, France. pp. 159-194.

Farquhar, G.D., Caemmerer, S., and von Berry, J.A. 1980. A biochemical model of photosynthetic $\mathrm{CO}_{2}$ assimilation in leaves of C3 species. Planta, 149: 78-90.

Fernández, M.P., Norero, A., Vera, J.R., and Pérez, E. 2011. A functional-structural model for radiata pine (Pinus radiata) focusing on tree architecture and wood quality. Ann. Bot. 108: 1155-1178. doi:10.1093/aob/mcr156. PMID:21987452.

Fontes, L., Bontemps, J.-D., Bugmann, H., Van Oijen, M., Gracia, C., Kramer, K., Lindner, M., Roetzer, T., and Skovsgaard, J.P. 2010. Models for supporting forest management in a changing environment. For. Syst. 19: 8-29.

Forrester, D.I., and Albrecht, A.T. 2014. Light absorption and light-use efficiency in mixtures of Abies alba and Picea abies along a productivity gradient. For. Ecol. Manage. 328: 94-102. doi:10.1016/j.foreco.2014.05.026.

Forrester, D.I., Elms, S.R., and Baker, T.G. 2013a. Tree growth-competition relationships in thinned Eucalyptus plantations vary with stand structure and site quality. Eur. J. For. Res. 132: 241-252. doi:10.1007/s10342-012-0671-0.

Forrester, D.I., Collopy, J.J., Beadle, C.L., and Baker, T.G. 2013b. Effect of thinning, pruning and nitrogen fertiliser application on light interception and lightuse efficiency in a young Eucalyptus nitens plantation. For. Ecol. Manage. 288: 21-30. doi:10.1016/j.foreco.2011.11.024.

Gilliams, S., Van Orshoven, J., Muys, B., Kros, H., Heil, G.W., and Van Deursen, W. 2005. AFFOREST sDSS: a metamodel based spatial decision support system for afforestation of agricultural land. New For. 30: 33-53. doi:10.1007/s11056004-0761-z.

Gonçalves, J.L., de, M., Alvares, C.A., Higa, A.R., Silva, L.D., Alfenas, A.C., Stahl, J., et al. 2013. Integrating genetic and silvicultural strategies to minimize abiotic 
and biotic constraints in Brazilian eucalypt plantations. For. Ecol. Manage. 301: 6-27.

Grassi, G., Meir, P., Cromer, R., Tompkins, D., and Jarvis, P.G. 2002. Photosynthetic parameters in seedlings of Eucalyptus grandis as affected by rate of nitrogen supply. Plant. Cell Environ. 25: 1677-1688. doi:10.1046/j.1365-3040. 2002.00946.x.

Griffon, S., and de Coligny, F. 2014. AMAPstudio: an editing and simulation software suite for plants architecture modelling. Ecol. Modell. 290: 3-10. doi:10.1016/j.ecolmodel.2013.10.037.

Gspaltl, M., Bauerle, W., Binkley, D., and Sterba, H. 2013. Leaf area and light use efficiency patterns of Norway spruce under different thinning regimes and age classes. For. Ecol. Manage. 288: 49-59. doi:10.1016/j.foreco.2011.11.044. PMID:25540477.

$\mathrm{Gu}, \mathrm{L} .2002$. Advantages of diffuse radiation for terrestrial ecosystem productivity. J. Geophys. Res. 107(D6): ACL-2-1-ACL-2-23. doi:10.1029/2001JD001242.

Hanson, P.J., Amthor, J.S., Wullschleger, S.D., Wilson, K.B., Grant, R.F., Hartley, A., Hui, D., Hunt, E.R., Jr, Johnson, D.W., and Kimball, J.S. 2004. Oak forest carbon and water simulations: model intercomparisons and evaluations against independent data. Ecol. Monogr. 74: 443-489. doi:10.1890/034049 .

Härkönen, S., Pulkkinen, M., Duursma, R., and Mäkelä, A. 2010. Estimating annual GPP, NPP and stem growth in Finland using summary models. For. Ecol. Manage. 259: 524-533. doi:10.1016/j.foreco.2009.11.009.

Härkönen, S., Lehtonen, A., Eerikäinen, K., Peltoniemi, M., and Mäkelä, A. 2011. Estimating forest carbon fluxes for large regions based on process-based modelling, NFI data and Landsat satellite images. For. Ecol. Manage. 262: 2364-2377. doi:10.1016/j.foreco.2011.08.035.

Hegyi, F. 1974. A simulation model for managing jack-pine stands. In Growth models for tree and stand simulation. Edited by J. Fries. Royal College of Forestry, Stockholm, Sweden. pp. 74-90.

Jackson, R.B., Canadell, J., Ehleringer, J.R., Mooney, H.A., Sala, O.E., and Schulze, E.D. 1996. A global analysis of root distributions for terrestrial biomes. Oecologia, 108(3):389-411.

Keenan, T., Sabate, S., and Gracia, C. 2008. Forest eco-physiological models and carbon sequestration. In Managing forest ecosystems: the challenge of climate change. Edited by F. Bravo, V. LeMay, R. Jandl, and K. von Gadow. Springer, Dordrecht, Netherlands. pp. 83-102.

King, D.A. 1997. The functional significance of leaf angle in Eucalyptus. Aust. J. Bot. 45: 619-639. doi:10.1071/BT96063.

Lafond, V., Cordonnier, T., and Courbaud, B. 2015. Reconciling biodiversity conservation and timber production in mixed uneven-aged mountain forests: identification of ecological intensification pathways. Environ. Manage. 56(5): 1118-1133. doi:10.1007/s00267-015-0557-2.

Landsberg, J.J., and Sands, P. 2010. Modelling tree growth: concepts and review. In Physiological ecology of forest production: principles, processes and models. Academic Press Inc., San Diego, California. pp. 221-241.

Landsberg, J.J., and Waring, R.H. 1997. A generalised model of forest productivity using simplified concepts of radiation-use efficiency, carbon balance and partitioning. For. Ecol. Manage. 95: 209-228. doi:10.1016/S0378-1127(97) 00026-1.

le Maire, G., Davi, H., Soudani, K., Francois, C., Le Dantec, V., and Dufrene, E. 2005. Modeling annual production and carbon fluxes of a large managed temperate forest using forest inventories, satellite data and field measurements. Tree Physiol. 25: 859-872. doi:10.1093/treephys/25.7.859. PMID:15870054

le Maire, G., Marsden, C., Verhoef, W., Ponzoni, F.J., Lo Seen, D., Bégué, A., Stape, J.L., and Nouvellon, Y. 2011. Leaf area index estimation with MODIS reflectance time series and model inversion during full rotations of Eucalyptus plantations. Remote Sens. of Environ. 115: 586-599. doi:10.1016/j.rse.2010. 10.004.

le Maire, G., Nouvellon, Y., Christina, M., Ponzoni, F.J., Gonçalves, J.L.M., Bouillet, J.P., and Laclau, J.P. 2013. Tree and stand light use efficiencies over a full rotation of single- and mixed-species Eucalyptus grandis and Acacia mangium plantations. For. Ecol. Manage. 288: 31-42. doi:10.1016/j.foreco.2012. 03.005.

Mailly, D., Turbis, S., and Pothier, D. 2003. Predicting basal area increment in a spatially explicit, individual tree model: a test of competition measures with black spruce. Can. J. For. Res. 33: 435-443. doi:10.1139/x02-122.

Makela, A., Landsberg, J., Ek, A.R., Burk, T.E., Ter-Mikaelian, M., Agren, G.I., Oliver, C.D., and Puttonen, P. 2000. Process-based models for forest ecosystem management: current state of the art and challenges for practical implementation. Tree Physiol. 20: 289-298. doi:10.1093/treephys/20.5-6.289. PMID: 12651445.

Marie, G., and Simioni, G. 2014. Extending the use of ecological models without sacrificing details: a generic and parsimonious meta-modelling approach. Methods Ecol. Evol. 5: 934-943. doi:10.1111/2041-210X.12250.

Marino, S., Hogue, I.B., Ray, C.J., and Kirschner, D.E. 2008. A methodology for performing global uncertainty and sensitivity analysis in systems biology. J. Theor. Biol. 254: 178-196. doi:10.1016/j.jtbi.2008.04.011. PMID:18572196.

Marrel, A., Iooss, B., Laurent, B., and Roustant, O. 2009. Calculations of Sobol indices for the Gaussian process metamodel. Reliab. Eng. Syst. Saf. 94: 742751. doi:10.1016/j.ress.2008.07.008.

Marsden, C., Nouvellon, Y., Laclau, J.-P., Corbeels, M., McMurtrie, R.E., Stape, J.L.,
Epron, D., and le Maire, G. 2013. Modifying the G'DAY process-based model to simulate the spatial variability of Eucalyptus plantation growth on deep tropical soils. For. Ecol. Manage. 301: 112-128. doi:10.1016/j.foreco.2012.10.039.

Mc Millen, G.G., and McClendon, J.H. 1979. Leaf angle: an adaptive feature of sun and shade leaves. Bot. Gaz. 140: 437-442. doi:10.1086/337110.

Mckay, M.D., Beckman, R.J., and Conover, W.J. 2000. A comparison of three methods for selecting values of input variables in the analysis of output from a computer code. Technometrics, 42: 55-61.

Medlyn, B.E. 1998. Physiological basis of the light use efficiency model. Tree Physiol. 18: 167-176. doi:10.1093/treephys/18.3.167. PMID:12651386.

Medlyn, B.E. 2004. A maestro retrospective, in: Mencuccini, M., Grace J, Moncrieff, J., KG, M. (Eds.), Forests at the Land-Atmosphere Interface. CABI Publishing, Wallingford, UK, pp. 105-122.

Medlyn, B.E., Pepper, D.A., O'Grady, A.P., and Keith, H. 2007. Linking leaf and tree water use with an individual-tree model. Tree Physiol. 27: 1687-1699. doi:10.1093/treephys/27.12.1687. PMID:17938100.

Norman, J.M., and Welles, J.M. 1983. Radiative transfer in an array of canopies. Agron. J. 75: 481-488. doi:10.2134/agronj1983.00021962007500030016x.

Nouvellon, Y., Laclau, J.P., Epron, D., le Maire, G., Bonnefond, J.M., Goncalves, J.L.M., and Bouillet, J.P. 2012. Production and carbon allocation in monocultures and mixed-species plantations of Eucalyptus grandis and Acacia mangium in Brazil. Tree Physiol. 32: 680-695. doi:10.1093/treephys/tps041. PMID:22588515.

O'Brien, S.T., Hubbell, S.P., Spiro, P., Condit, R., and Foster, R.B. 1995. Diameter, height, crown, and age relationship in eight neotropical tree species. Ecology, 76: 1926-1939.

Ogle, K., Lucas, R.W., Bentley, L.P., Cable, J.M., Barron-Gafford, G.A., Griffith, A., Ignace, D., Jenerette, G.D., Tyler, A., Huxman, T.E., Loik, M.E., Smith, S.D., and Tissue, D.T. 2012. Differential daytime and night-time stomatal behavior in plants from North American deserts. New Phytol. 194: 464-476. doi:10.1111/ j.1469-8137.2012.04068.x. PMID:22348404.

Pretzsch, H., Grote, R., Reineking, B., Rötzer, T., and Seifert, S. 2008. Models for forest ecosystem management: a European perspective. Ann. Bot. 101: 10651087. PMID:17954471.

Richards, A.E., and Schmidt, S. 2010. Complementary resource use by tree species in a rain forest tree plantation. Ecol. Appl. 20: 1237-1254. doi:10.1890/091180.1. PMID:20666247.

Seidl, R., Lexer, M.J., Jager, D., and Honninger, K. 2005. Evaluating the accuracy and generality of a hybrid patch model. Tree Physiol. 25: 939-951. doi:10.1093/ treephys/25.7.939. PMID:15870060.

Sieber, S., Amjath-Babu, T.S., Jansson, T., Müller, K., Tscherning, K., Graef, F., Pohle, D., Helming, K., Rudloff, B., Saravia-Matus, B.S., and Gomez y Paloma, S. 2013. Sustainability impact assessment using integrated meta-modelling: simulating the reduction of direct support under the EU common agricultural policy (CAP). Land use policy 33: 235-245.

Smith, R.C. 2013. Uncertainty quantification: theory, implementation, and applications. SIAM.

Sobol, I.M. 1993. Sensitivity analysis for nonlinear mathematical models. Math. Model. Comput. Exp. 1: 407-414.

Spitters, C.J.T., Toussaint, H., and Goudriaan, J. 1986. Separating the diffuse and direct component of global radiation and its implications for modeling canopy photosynthesis. Part I. Components of incoming radiation. Agric. For. Meteorol. 38: 217-229.

Tian, W. 2013. A review of sensitivity analysis methods in building energy analysis. Renewable Sustainable Energy Rev. 20: 411-419. doi:10.1016/j.rser.2012. 12.014

Tuzet, A., Perrier, A., and Leuning, R. 2003. A coupled model of stomatal conductance, photosynthesis and transpiration. Plant. Cell Environ. 26: 10971116. doi:10.1046/j.1365-3040.2003.01035.x.

Vanclay, J.K. 2006. Spatially-explicit competition indices and the analysis of mixed-species plantings with the Simile modelling environment. For. Ecol. Manage. 233: 295-302. doi:10.1016/j.foreco.2006.05.020.

Whitehead, D., and Beadle, C.L. 2004. Physiological regulation of productivity and water use in Eucalyptus: a review. For. Ecol. Manage. 193: 113-140. doi: 10.1016/j.foreco.2004.01.026.

Williams, M., Rastetter, E.B., Fernandes, D.N., Goulden, M.L., Wofsy, S.C., Shaver, G.R., Melillo, J.M., Munger, J.W., Fan, S.-M., and Nadelhoffer, K.J. 1996. Modelling the soil-plant-atmosphere continuum in a Quercus-Acer stand at Harvard Forest: the regulation of stomatal conductance by light, nitrogen and soil/plant hydraulic properties. Plant Cell Environ. 19: 911-927. doi:10. 1111/j.1365-3040.1996.tb00456.x.

Wullschleger, S.D. 1993. Biochemical limitations to carbon assimilation in C3 plants - a retrospective analysis of the A/Ci curves from 109 species. J. Exp. Bot. 44: 907. doi:10.1093/jxb/44.5.907.

Zeppel, M., Tissue, D., Taylor, D., Macinnis-Ng, C., and Eamus, D. 2010. Rates of nocturnal transpiration in two evergreen temperate woodland species with differing water-use strategies. Tree Physiol. 30: 988-1000. doi:10.1093/treephys/ tpq053. PMID:20566582.

Zhou, X., Zhang, Y., Ji, X., Downing, A., and Serpe, M. 2011. Combined effects of nitrogen deposition and water stress on growth and physiological responses of two annual desert plants in northwestern China. Environ. Exp. Bot. 74: 1-8. doi:10.1016/j.envexpbot.2010.12.005. 